Ethiopian Journal of Environmental Studies \& Management 8(3): 318 - 329, 2015.

ISSN:1998-0507

doi: http://dx.doi.org/10.4314/ejesm.v8i3.9

Submitted: January 24, 2015

Accepted: March 31, 2015

\title{
ASSESSMENT OF THREAT STATUS IN THE NORTHERN WOODLANDS OF THE BALE MOUNTAINS, ETHIOPIA: INDICATOR FOR MANAGEMENT EFFECTIVENESS
}

\section{*ADDISU ASEFA,1 ANTENEH SHIMELIS² AND ANOUSKA A. KINAHAN3}

${ }^{1}$ Bale Mountains National Park, Po Box 107, Bale-Goba, Ethiopia

${ }^{2}$ Addis Ababa University, Deportment of Zoological Science, Po Box 1176, Addis Ababa, Ethiopia

${ }^{3}$ Frankfurt Zoological Society-Bale Mountains Conservation Project, Po Box 165, Bale-Robe, Ethiopia

* Corresponding author, Current address: Ethiopian Wildlife Conservation Authority, Po Box 386, Addis Ababa, Ethiopia.

\begin{abstract}
The present study was carried out to identify the types and quantify the magnitude of human disturbances in six forest patches in the northern Bale Mountains, southeast Ethiopia. The principal objective was to compare three protected forest patches within the Bale Mountains National Park with three unprotected patches outside the park in terms of the severity of human-induced disturbances. Data was collected along five 1-km long transects in each patch. Eight major disturbance types were identified and quantified in the six forest patches: settlement, agriculture, selective logging, livestock herbivory, fuel wood collection, charcoal production, path/track formation and forest-fire. Results showed some degree of human disturbances in all patches, with logging, fuel wood collection, path/track formation and livestock grazing being the most widespread. Crop production, settlement and charcoal making, however, were only recorded in unprotected patches. Sixty percent and $47 \%$ of transects in these patches showed crop cultivation and houses respectively, covering $40 \% \mathrm{ha}^{-}$ 1. The unprotected patches were characterized by significantly higher level of incidences of logged trees, fuel wood collection and livestock herbivory compared to the protected patches. For tree logging, this difference was however only observed for trees logged in recent years (estimated to be logged $<20$ years) with logging of larger trees (DBH > $10 \mathrm{~cm})$ than smaller trees. Generally the protected areas had reduced human disturbance as indicated by low logging activity. This is a positive indicator of effective management practices in the protected area.
\end{abstract}

Key Words: Bale Mountains, Disturbance, Logging, Management effectiveness, Threat.

\section{Introduction}

National Parks and Nature Reserves are important tools for global, regional and national conservation policies and strategies, and such areas are under increasing threat from growing human populations (van Schaik et al., 1997;

*Corresponding Author: Addisu Asefa

Email: aa.mitiku@gmail.com
Struhsaker et al., 2005; Bleher et al., 2006). A survey conducted on 201 parks across 16 tropical countries revealed that more than $70 \%$ are being affected by poaching, livestock herbivory, settlement, agriculture and logging (van Schaik et al., 1997). As a result, improving threat management 318 
strategies is becoming increasingly a priority for conservation practitioners. To do this, obtaining detailed information on the types and intensities of disturbances and/or the impact on biodiversity of such threats is required (Stephens et al., 2001; Struhsaker et al., 2005; Bleher et al., 2006; Newton, 2007). Although having both data sets (threats and their impacts) is of paramount importance for effective conservation, information on threats to biodiversity in protected areas should be of greater priority than acquiring data on their impacts (Bleher et al., 2006). This is because there is usually a time-lag between the occurrence of disturbances and the response of biodiversity (Bleher et al., 2006; Newton, 2007). Thus, the presence of data on such threats help managers be proactive rather than taking reactive conservation measures. Conversely, reliance on impact information for management decision could lead to delayed management actions if the response of biodiversity is not detected immediately after the occurrence of the threats (Newton, 2007). Also most protected areas, particularly in developing tropical countries, lack resources (financial and expertise) to undertake thorough biodiversity inventories to detect responses. Thus, collecting data on the spatial and temporal scale of threats is supposed to be simper and help in practicing adaptive management system (Bleher et al., 2006).

Despite the importance of having quantitative threat data for effective conservation management, a surprisingly little attention has been given to it by researchers, and many conservation practices are based on tradition or experiences of practitioners rather than on the results of scientific research (Parrish et al., 2003; Newton, 2007; Chown, 2010). This paper presents results from a survey that quantified human-induced threats in differently managed dry Afromontane forest patches in the northern Bale Mountains, southeast Ethiopia.

The Bale Mountains region is one of the few places in Ethiopia that contain the last relatively intact Afromontane forests remaining in the highlands of the country (NH, 2004; Williams et al., 2004). The Bale Mountains are recognized as part of the Eastern Afromontane biodiversity hotspot by Conservation International (Williams et al., 2004), and as a centre of diversity and endemism, where many of the plant and animal species are also locally endemic to the mountains themselves $(\mathrm{NH}$, 2004; Asefa, 2007, 2011; Largen and Spawls, 2011). The ecological importance of the region was acknowledged by establishment of the Bale Mountains National Park (BMNP) at the heart of these mountains in 1971. The BMNP is considered as an important site for the conservation of ecological and hydrological systems, and the rare, threatened and endemic floral and faunal species of the region (Hillman, 1986; OARDB, 2007). However, like so many of Africa's protected areas (Struhsaker et al., 2005), it has been under increasing pressure from an ever-growing human population in the surrounding areas (Hillman, 1986; Miehe and Miehe, 1994; Stephens et al., 2001; OARDB, 2007). The Bale Mountains area was virtually uninhabited prior to $1960 \mathrm{~s}$ (Hillman, 1986). Reports indicate that the estimated number of human population in the BMNP boundary was about 500 people in 1960s, 2500 in 1980s (Hillman, 1986; Miehe and Miehe, 1994) and, with a dramatic increase since 1990s to approximately 20000 at present (OARDB, 2007).

The northern slope of the BMNP is covered by six patches of woodland forest, which is characterized as Dry evergreen Afromontane forest vegetation type (Mitiku, 2013). The forests' vegetation is dominated by two indigenous tree species, 
Hagenia abyssinica and Juniperus procera, but Hypericum revoltum and Rappanea simensis also abundantly occur at higher elevations (Hillman, 1986). In addition to the ecosystem services such as carbon sequestration, these forest patches are critical habitats for a number of conservation significant mammal and bird species, including the endangered endemic antelope - the Mountain Nyala (Tragelaphus buxtoni) (Hillman, 1996; Mitiku, 2013). A quantitative assessment of the disturbances occurring in the forests will enable managers of the area to: 1 ) track any changes occurring in the forests; 2 ) to take proactive measures as the disturbance information acts as an early warning system; and, 3) evaluate their management effectiveness. Although the spatial patterns in the types and severity of forest disturbances has not been quantitatively determined yet, a study on the land cover changes in the Bale mountains showed that the highest rate of forest reduction was detected in the last 20 years (Teshome et al., 2011), coinciding with the period when most of the country's protected areas began experiencing unprecedented severe degradation (Abunie, 2000; Amente, 2005).

The objectives of our research were to: (1) identify the types and quantify the intensities of the major human-induced disturbances across all forest patches; (2) evaluate the effectiveness of conservation measures in the protected forests by examining the differences in human disturbance levels with unprotected forest patches; and, (3) provide a baseline for the long term monitoring of human disturbance parameters in these forests. Given the difference in protection priority among the patches and the rapid rate of forest destruction in the Bale mountains in recent times than in the past, we hypothesized such disturbances may occur at lower levels in the protected (those falling in the BMNP) than in those found outside the park, and if this is true, we hypothesized that the difference in disturbance level between the protected and unprotected forests might be better revealed for disturbances occurring in recent time $(\sim<$ 20 years) than for past.

\section{Study Area}

The Bale Mountains region is located $400 \mathrm{~km}$ southeast of Addis Ababa, the capital of Ethiopia. It forms part of the Bale-Arsi massif in the south-eastern Ethiopian Highlands and covers 22,176 $\mathrm{km}^{2}$ of which $2200 \mathrm{~km}^{2}$ designated as the BMNP (Figure1). The region encompassing a landscape that ranges in altitude from 1500 to $4377 \mathrm{~m}$ asl (Hillman, 1986), and experiences two rainy seasons, known locally as the heavy and small rains. The heavy rains last from July to October, with the highest peak in August, while the small rains last from March to June, with a peak in April. Five broad vegetation zones occur in the Bale Mountains eco-region, namely the northern grasslands (a flat area at altitude of $3000 \mathrm{~m}$ asl), the northern dry ever green Afromontane forest (2900-3400 $\mathrm{m}$ asl), ericaceous forest (3400-3800 $\mathrm{m}$ asl), the Afroalpine moorland and grassland (3800-4377 $\mathrm{m}$ asl), and the southern Harenna forest (1500-3200 m asl; Hillman, 1986; NH, 2004; OARDB, 2007).

The present study was carried out in the northern forest of the Bale Mountains between July and September 2011, which is generally classified as dry evergreen Afromontane forest vegetation type. This forest exists in six isolated patches between altitudes of 2900-3450 m asl (Figure 1). Three of the patches (Dinsho Hill, Adellay and Boditti) are situated inside the BMNP (hereafter referred to as protected forest patches) and have been actively protected from illegal human disturbances through ranger-based patrolling activities, patrolling effort estimated to be 40 man-hour per day, since the establishment of the BMNP (Mitiku, 2013). However, the other three 
(Shaya, Angesso and Darkina) are situated outside the national park (hereafter referred to as unprotected) and have been managed by Woreda (District) forestry departments. With a patrolling effort of 0.4 man-hour per day, little if any law enforcement has occurred in these areas (Hillman, 1986; OARDB, 2007; Mitiku, 2013).

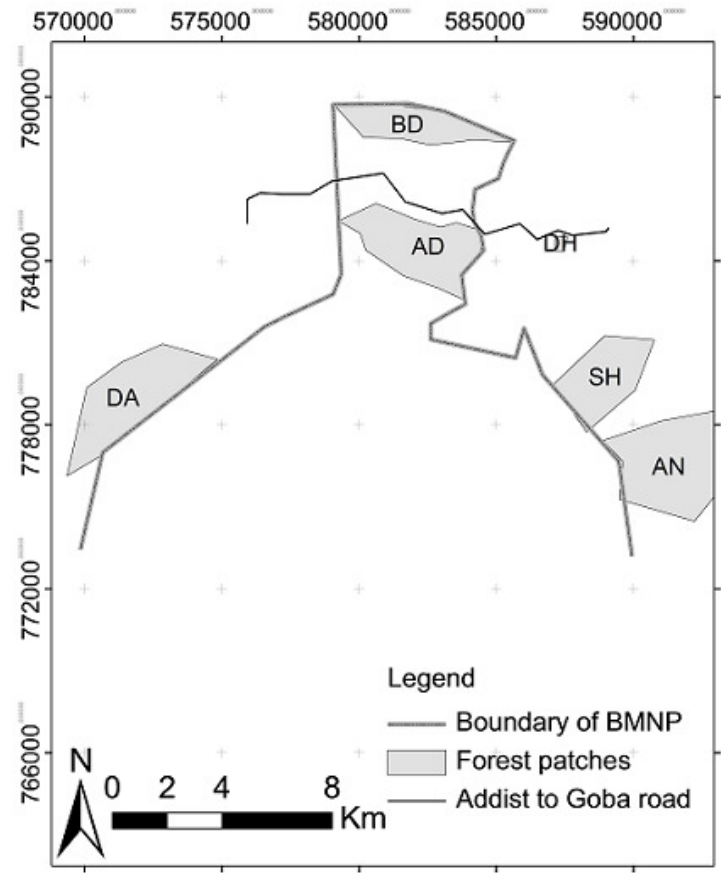

Figure 1. Map of the Bale Mountains National Park (only partly shown) and the six forest patches studied. Abbreviations of the patches: $\mathrm{AN}=$ Angesso; $\mathrm{SH}=$ Shaya; $\mathrm{DH}=$ Dinsho Hill (BMNP HQs); $\mathrm{AD}=$ Adellay; $\mathrm{BD}=$ Boditti; and DA = Darkina.

\section{Methodology \\ Data Collection}

Prior to the actual data collection, preliminary assessment was done to identify the difference types of disturbances encountered across the forest patches Eight major disturbance types were identified across all forest patches as follows; settlement, agriculture, selective logging, livestock herbivory, fuel wood collection, charcoal production, abandoned and current paths/tracks used by locals and number of forest fire evidences. Five transects of $\sim 1$ $\mathrm{km}$ long were systematically established in each patch, the first and the last transects being $50 \mathrm{~m}$ away from forest edges. The number of incidence of each disturbance type were counted and recorded within a belt of $15 \mathrm{~m}$ on either side of each transect except for three variables (cultivation, settlement and herbivory). For livestock herbivory we used four $20 \times 20 \mathrm{~m}^{2}$ quadrats established at regular intervals along each transect. Herbivory levels were estimated using an ordinal scale as: $1=$ no herbivory; 2 = light; 3 = moderate; and $4=$ heavy, based on the indicators of different herbivory pressures proposed by Newton (2007). At each of these quadrats the proportion of visible land under cultivation was estimated and the number of houses present counted within a $100 \mathrm{~m}$ radius.

In case of logging detailed data was recorded: species identity, number, age and size of tree stumps within a belt of $15 \mathrm{~m}$ on either side of each transect. For each tree stump the base circumference was measured using rubber tape meter to calculate its base diameter which assumed to represent approximate size of diameter at breast height $(\mathrm{DBH})$ of each stump (Bleher et al., 2006). DBH was calculated as follows: $D B H=C / \pi$; where, $C$ is a stump circumference; and $\pi$ is a constant equal to $\sim$ 3.14. Trees with a DBH of less than 10 $\mathrm{cm}$ were assumed to be cut and used mostly for fencing and pole, and trees with a DBH of more than $10 \mathrm{~cm}$ were assumed to be cut and used for house walling and timber/lumber (used for production of doors, windows and other house furniture). For each stump the approximate time since cutting (i.e., stump age) was subjectively estimated to be either more than 20 years or less than 20 years, respectively, for a distinction between past and recent logging. Age was estimated according to the degree of decomposition and the shape of the remaining tree stump (for detail on this see, Bleher et al., 2006; Newton, 2007), 


\section{Data Analysis}

Density (and percent cover in the case of cultivation) of each disturbance parameter, except herbivory, was calculated for each land use type (protected vs. unprotected) separately by dividing the total number of events of disturbance type recorded to the total area surveyed. Since data for most of the variables were nonnormally distributed, the influence of protection status on each disturbance variables with counting data was tested using Mann-Whitney $U$-tests $(U)$. This is a non-parametric test that does not require the assumptions of homogeneity of variance and normality of means (Quinn and Keough, 2002). Difference in level of herbivory between the protected and unprotected forests was tested using chisquare test. For selective tree logging, the influence of protection status was tested separately on the number of logged trees of the two different age classes (trees assumed to be logged in the recent years, and trees logged in the past), and the two different size classes $(\mathrm{DBH}<10 \mathrm{~cm}$, and $\mathrm{DBH}>10$ $\mathrm{cm})$. All the analyses were carried out in SPSS soft-ware version 20.

\section{Results}

\section{Overall Disturbance}

Of the eight disturbance types encountered across all forest patches, three of them (crop production, settlement and charcoal production) were only recorded in the unprotected forests (Table 1). Of the 15 transects sampled in the unprotected forests, houses were encountered along seven of them $(47 \%)$ and crop cultivation along nine $(60 \%)$ with mean values of 2.7 houses and $40 \%$ cover $\mathrm{ha}^{-1}$, respectively. Charcoal production was encountered along all transects of the unprotected forests, with a total of 20 incidences. Tree logging, herbivory, fuel wood collection and footpath/cattle track were found to be the most widespread disturbance types in the area, they were encountered along all transects of each patch. However, only two incidences of forest fire along a single transect was encountered in the protected forests, while with 14 incidences along four $(80 \%)$ transects in the unprotected forests.

\section{Logging}

Over a total survey area of $\sim 69$ ha, 4536 logged trees [tree stumps] were found exclusively from four species, Juniperus procera (33.5 trees logged per hectare) and Rappanea simensis (21.2), Hypericum revoltum (9.2) and Hagenia abyssinica (1.8). Tree logging was significantly in lower numbers in the protected forests compared to unprotected forests (Figure 2; $\mathrm{U}=0.000, \mathrm{P}<0.01)$. However, separate analysis of the two size classes of tree stumps showed that a significant difference in number of stumps between the forests with different protection status was observed only for large-sized (DBH $>10$ $\mathrm{cm}) \operatorname{logs}$ (protection status: DBH $>10 \mathrm{~cm}$ : $\mathrm{U}=-0.000, \mathrm{P}<0.01 ; \mathrm{DBH}<10 \mathrm{~cm} \mathrm{U}=$ $0.300, \mathrm{P}>0.01$; Figure 2). 
Table 1: Number of disturbance events per ha recorded in the protected and unprotected forests in the northern Bale Mountains of Ethiopia.

\begin{tabular}{|c|c|c|c|c|c|c|c|}
\hline $\begin{array}{l}\text { Protection } \\
\text { status }\end{array}$ & $\begin{array}{l}\text { No. trees logged/ha } \\
(>20 \text { years })\end{array}$ & $\begin{array}{l}\text { No. trees } \\
\text { logged/ha }(<20 \\
\text { years })\end{array}$ & $\begin{array}{l}\text { No. total trees } \\
\text { logged/ha }\end{array}$ & $\begin{array}{l}\text { No. charcoal } \\
\text { kilns/ha }\end{array}$ & $\begin{array}{l}\text { No. paths and/or } \\
\text { cattle tracks/ha }\end{array}$ & $\begin{array}{l}\text { No. fuel } \\
\text { wood/ha }\end{array}$ & $\begin{array}{l}\text { No. signs of } \\
\text { fire/ha }\end{array}$ \\
\hline Protected & 18.4 & 21.9 & 40.3 & 0 & 3.8 & 2.6 & 0.3 \\
\hline Unprotected & 27.8 & 73.7 & 101.5 & 2.6 & 4.2 & 9.1 & 1.7 \\
\hline
\end{tabular}




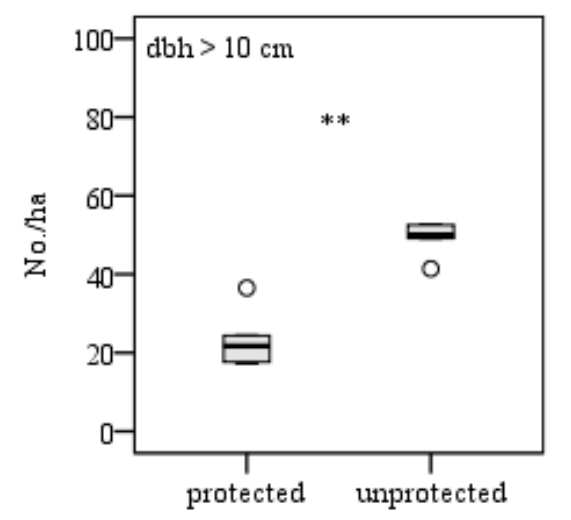

all cases, $\mathrm{U}=4.000-5.000, \mathrm{P}>0.05)$. In contrast, recently logged trees showed a significant difference with fewer trees logged at the protected forests (Figure 4; protection status $\mathrm{U}=0.000, \mathrm{P}<0.01)$. However, when the two size classes were separately compared for the recent logging, this significant difference was found only for large trees $(\mathrm{DBH}>10 \mathrm{~cm})$ (large stumps ha ${ }^{-1}$, protection status: $\mathrm{U}=0.000, \mathrm{P}$ $<0.01$; small stumps $\mathrm{ha}^{-1}$, protection status:

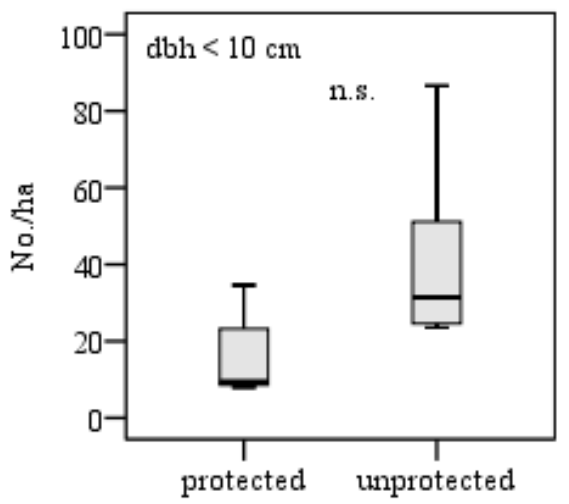
$\mathrm{U}=4.000, \mathrm{P}>0.05$; Figure 4).
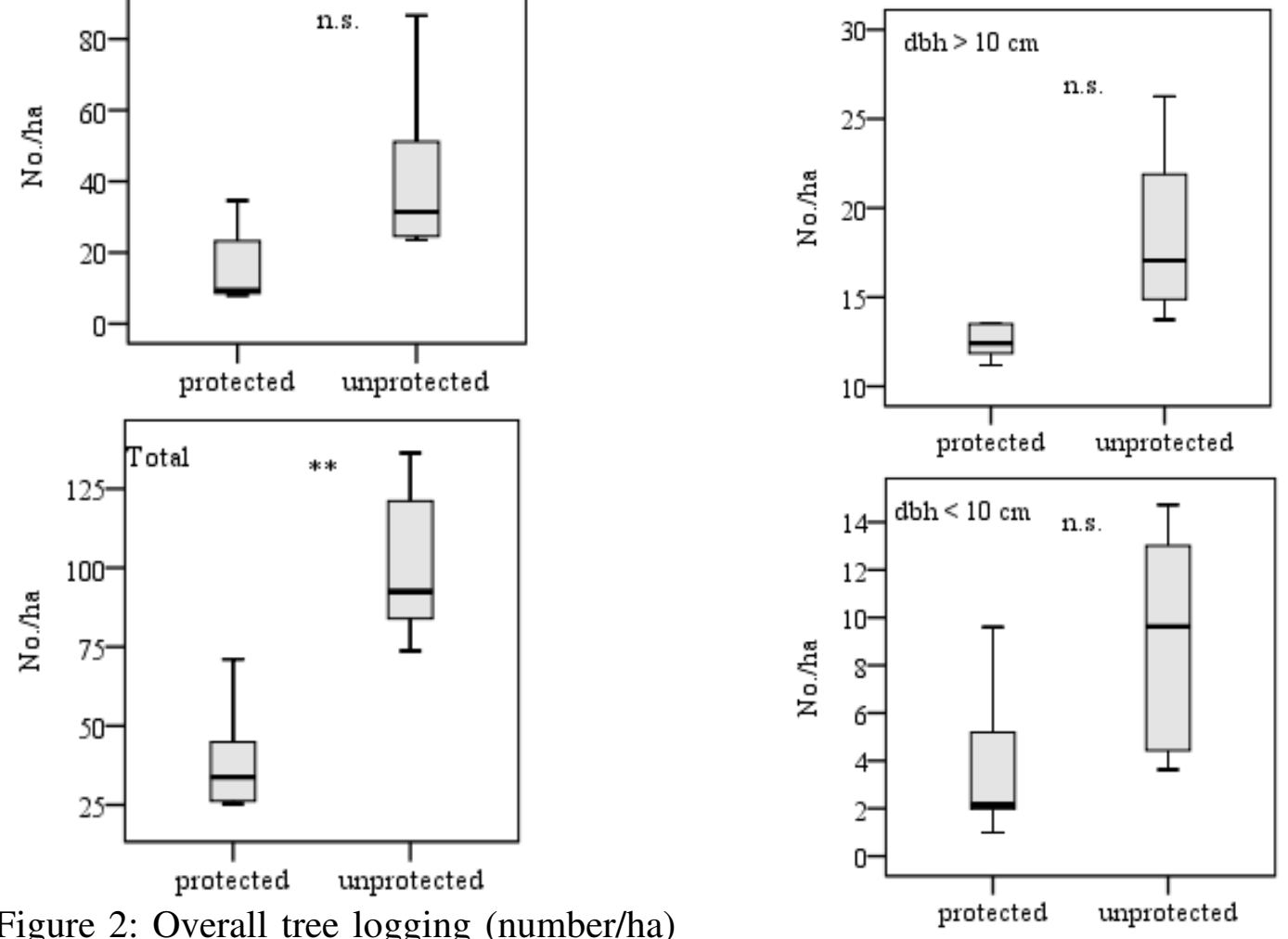

Figure 2: Overall tree logging (number/ha) in the protected and unprotected forest patches. Given are medians and quartiles, minimum and maximum values (outliers are represented by individual points as 'o' symbol) and significance levels (as: n.s. = non-significant; $* *=\mathrm{P}<0.05$ ).

When past and present logging activities were separately considered, protection status had no significant influence on the number of trees logged in the past (i.e. logging before 20 years) either when stumps of the two size classes were treated separately or together (Figure 3; in

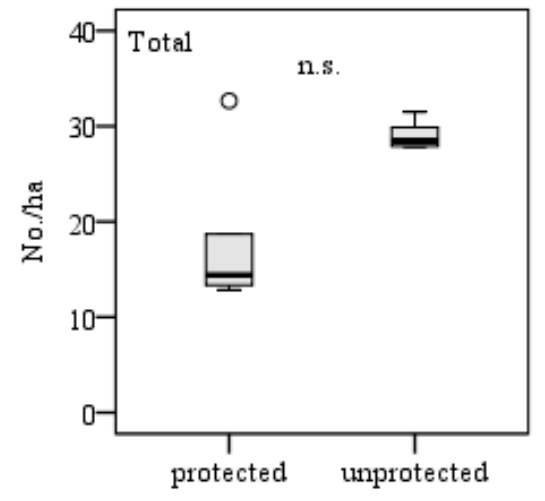

Figure 3: Trees logged (number per ha) more than 20 years ago in the protected and unprotected forest patches. Given are 
medians and quartiles, minimum and maximum values (outliers are represented by individual points as 'o' symbol) and significance levels (as: n.s. = nonsignificant; $* *=\mathrm{P}<0.05)$.
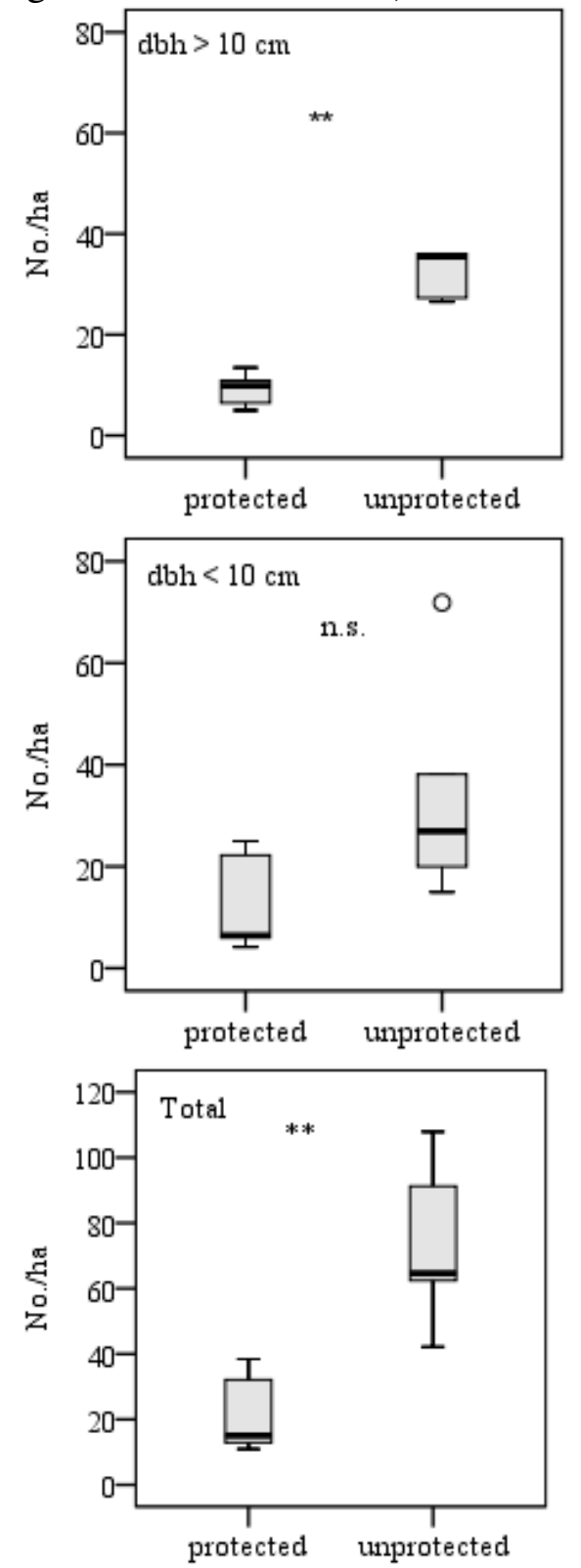

Figure 4: Trees logged in the last 20 years (number/ha) in the protected and unprotected forest patches. Given are medians and quartiles, minimum and maximum values (outliers are represented by individual points as 'o' symbol)and significance levels (as: n.s. $=$ not significant; $* *=\mathrm{P}<0.05)$.
Fuel wood, herbivory and path/track disturbance

Significant differences were observed for fuel wood collection and herbivory levels between the two categories of forest patches with lower incidences in the protected forests (fuel wood collection/ha: protected forests, median $=2.98, \mathrm{q} 1=1.42$, q3 $=3.65$, range 1.3-3.7; unprotected forests, median $=7.14, \mathrm{q} 1=6.07, \mathrm{q} 3=$ 13.04, range 5.5-16.3; $\mathrm{U}: \mathrm{Z}=-2.611, \mathrm{P}=$ 0.087 ; herbivory: $X^{2}$ - value $=13.86$, d.f. $=$ $3, \mathrm{P}<0.01)$. Signs of herbivory were recorded in $57(95 \%)$ of the quadrats surveyed in the unprotected forests and 42 $(70 \%)$ in the protected forests. Of these, $5 \%$ and $5 \%$ of them in the unprotected forests, and $20 \%$ and $45 \%$ in the protected forests, were categorized to be heavy and light herbivory levels, respectively. However, when the frequencies of the different herbivory levels were compared separately between the two land use types, a significant difference was found only for heavy herbivory level $(\chi 2=7.847$, d.f. $=1$, $\mathrm{P}<0.05$ ).

No significant difference was found between the two forest categories in terms of the number of foot path/track events per hectare (track/ha: protected forests median $=3.12, \mathrm{q} 1=2.46, \mathrm{q} 3=5.48$, range 1.9-5.9; unprotected forests: median $=4.18, \mathrm{q} 1=$ 2.52 , q3 $=5.97$, range $2.5-6.5 ; \mathrm{U}: \mathrm{Z}=$ $0.313, \mathrm{P}>0.05)$.

\section{Discussion}

Results showed that some humaninduced disturbances are present across all forest patches surveyed (e.g. logging, livestock herbivory, fuel wood collection and path/track formation), while some others disturbance types were found to be either rare events (e.g. forest fire) or are only encountered in the unprotected forest patches (crop cultivation, settlement and charcoal production). Previous subjective ranking exercise conducted, based on the 
opinions of researchers and conservationists, on the severity of the different threats in these forests indicated that logging was ranked 'very high', agriculture expansion and livestock herbivory 'high', and others like settlement expansion and non-woody material collection moderate to low (OARDB, 2007). Thus, the present findings provided a quantitative substantiate to the opinions reflected previously by various researchers (Hillman, 1986; NH, 2004; Amente, 2005; Demissie, 2007; OARDB, 2007; Teshome, et al., 2011; Mitiku, 2013). This study further found that unlike the protected forests that are relatively under high protection status, those forests found outside the BMNP are severely impacted from agricultural practices, settlement encroachments, fuel wood collection and logging activities, suggesting that law enforcement by the BMNP management might have relatively safeguarded the forests situated in the BMNP.

These data did not only demonstrate the present status of human disturbances in the forests, but also reflected management history, at least, for the last 20 years. The BMNP, in general, had not been appropriately managed until recently due to ill-staffing level and resource constraints (Hillman, 1986; OARDB, 2007). However, the northern section of the national park, including three of the six study forest patches belonging to it, has been relatively actively managed since the establishment of the national park in 1971. Four functional ranger outposts are there around these forests where daily ranger-based patrolling and monitoring of illegal activities are undertaken, Thus, it might be expected that both past and recent logging levels should be lower in the protected forests than their counterpart; however, a significant difference between them was found only for recent logging. This may imply that: (1) either previous conservation endeavours in the BMNP was not successful in the past; (2) regardless of their protection status, conservation effectiveness of both the BMNP and District forestry departments was similarly in the past,; and/or, (3) the BMNP has been more effective in managing the forests situated in the park in recent times. If the latter supposition holds true, the effectiveness of the BMNP was specifically revealed for trees $(\mathrm{DBH}>10 \mathrm{~cm})$ estimated to be logged in the last 20 years. In addition to the probable reasons discussed above, the difference found in recent logging level of larger tress between the two forest categories might be attributed to the fact that cutting and transporting of large-sized trees takes relatively longer time than small-/pole-sized trees, hence increasing the probability of tree poachers being confiscated by the park rangers in the forests situated in the BMNP. Thus, to avoid such risks tree poachers might tend to cut small trees in the protected forests. In contrast, in the forests situated outside the park, where there is no regular patrolling of illegal activities, logging seems to be done indiscriminately of tree size rather depends on the type of raw material demanded. This lack of regular ranger-based monitoring in the unprotected forests could have created a conducive environment for the surrounding communities to practice various other local -level threats such as charcoal making and forest fire. In general, the present findings that higher level of threats, particularly logging, in the forests with low conservation priority than their counterpart is similar to the results found by Bleher et al. (2006) in Kakamega forest, Kenya.

Intensities of herbivory and fuel wood collection were also found to be higher in the unprotected forests than the protected which also could be explained by the difference in protection level between the two forest groups. While the local community found living around the 
protected forests collect fuel wood mostly for domestic consumption, those living around the unprotected forests do so, including charcoal, both domestic use and for sale (first author's personal observations during the study period). The reason for catching forest fire in the unprotected forests was not clear. However, key informants informally explained that it is not done deliberately, rather is due to fire escaping from charcoal remains. Although differences in management-intensity between the two forest groups is assumed to be the most likely reason for the observed difference in the nature and severities of disturbances between the two differently managed forests in the present study area, it is to be noted however that other factors such as differences in accessibility or their proximity to neighbouring settlements and population density around the forest might be other potential factors associated with the differences observed (Brunner et al., 2001; Bleher et al., 2006). Thus, exploring the relationships between such potential factors and the level of disturbances observed is needed to further enhance our understanding of the underlying causes.

Although most of the disturbance types occur in both the protected and unprotected forests, in the present survey only logging appeared to be an effective indicator for human impact on the forests and might offer a valuable tool to conservation managers of the forests. First, some disturbances, such as charcoal production and forest fire were mostly found in the unprotected area, indicating only localized threats. Second, widespread threats such as herbivory and track/path formation done by livestock are confounded by those done by wildlife. Third, fuel wood collection is mostly made by extracting from remnants of trees and/or their branches primarily felled for timber production; hence, confounded with logging. Fourth, using logging as a disturbance indicator can enable us to differentiate between recent and past disturbances and might consequently help to evaluate past management effectiveness (Bleher et al., 2006). Finally, although several potential threats are facing protected areas globally, logging is reported to be the most widespread threat to protected areas throughout the tropics (van Schaik et al., 1997; Parrish et al., 2003).

\section{Conclusion and Recommendations}

Our results showed that human-induced disturbances are present across all the forest patches surveyed, with logging, livestock herbivory, fuel wood collection and path/track formation being the most widespread. All the disturbance types occurred either only or with greater incidences/levels in the unprotected forest compared to the protected ones. Although most of the disturbance types occurred in both the protected and unprotected forests, only logging appeared to be an effective indicator for human impact on the forests. It demonstrated not only the present status of human disturbances in the forests, but also enabled us assess past and present management effectiveness. In general, although lack of appropriate protection had resulted into more unregulated resource utilization in the unprotected forests, the protected forests were also found to be impacted from human disturbances.

Therefore, we recommend the following two key activities to be undertaken to ensure the long-term sustainable use and conservation of this forests: (1) strengthening the usual ranger patrolling actives in the protected forests; and, (2) devising strategies that would reduce over-exploitation of forest products in the unprotected forests. The latter could be achieved by designating the sites as community-based conservation forests so that people would use the resources in more 
regulated and sustainable way. Further, the dependence of local community on the forests for construction and other uses could be minimized by encouraging them plant fast growing exotic plants. In addition to these undertakings, repeated assessment of the disturbances in the forests especially logging, at regular intervals, would also be important to keep track of human impacts in the areas and to provide feedback to managers when evaluating past management decisions and setting up new conservation goals. Finally, we suggest that determining the impacts on the forests' bio-physical components of the disturbances is of paramount benefit to clearly understand their cause-effect relationships, providing a guiding tool to help decide appropriately on what tolerable limits might be and what mitigation measures would be taken.

\section{Acknowledgments}

We are grateful to Jemal Kassim and Usman Abdella for their assistance during the data collection. Data for this study was collected during a bird study in the area, a project funded by the Frankfurt Zoological Society-Bale Mountains Conservation Project. We are also thankful to the Ethiopian Wildlife Conservation Authority/Bale Mountains National Park for the study permission given.

\section{References}

Abunie, L. (2000). The Challenges of conserving Ethiopian wildlife: Overview. Walia, 21: 56-61.

Amente, G. (2005). Rehabilitation and sustainable use of degraded community forests in the Bale Mountains of Ethiopia. Freiburg imBreisgau, Germany: AlbertLudwigs-University.

Asefa, A. (2007). Birds of Bale Mountains National Park, Southeast Ethiopia. Walia, 25: 22-33.
Asefa, A. (2011). Mammals of the Bale Mountains National Park, Ethiopia: compiled and annotated checklist. Walia-Special Edition on the Bale Mountains, 3-14.

Bleher, B., Uster, D. and Bergsdorf, T. (2006). Assessment of threat status and management effectiveness in Kakamega Forest, Kenya. Biodiversity and Conservation, 15: 1159-1177.

Brunner, A.G., Gullison, R.E., Rice, R.E. and da Fonseca, G.A.B. (2001). Effectiveness of parks in protecting tropical biodiversity. Science, 291: 125-128.

Chown, S.L. (2010). Temporal biodiversity change in transformed landscapes: a southern African perspective. Philosophical Transactions of the Royal Society of London (B), 365: 3729-3742.

Demissie, A.M. (2007). Impact of human and livestock interference on the dynamics of vegetation structure and soil carbon: the case of northern part of Bale Mountains National Park, south-eastern highlands of Ethiopia. Mekelle, Ethiopia: Mekelle University.

Hillman, J.C. (1986). Bale Mountains National Park Management Plan. Addis Ababa, Ethiopia: Ethiopian wildlife conservation organization.

Largen, M. and Spawls, S. (2011). Amphibians and Reptiles Recorded from the Bale Mountains. WaliaSpecial Edition on the Bale Mountains, 89-91.

Miehe, G. and Miehe, S. (1994). Ericaceous forest and heath land in Bale Mountains of South Ethiopia, Ecology and Man's Impact. Hamburg, Germany: Traut Warnke Verlag.

Mitiku, A.A. (2013). Afromontane avian assemblages and land use in the Bale Mountains of Ethiopia: patterns, 
processes and conservation implications. Pretoria, South Africa: University of Pretoria.

Newton, A.C. (2007). Forest ecology and conservation: a handbook of techniques in ecology and conservation series. Oxford, United Kingdom: Oxford University Press.

NH (The National Herbarium) (2004). Biodiversity assessment of the Bale Mountains National Park and surrounding areas. Addis Ababa, Ethiopia: The National Herbarium, Addis Ababa University.

OARDB (2007). General Management Plan of the Bale Mountains National park (BMNP). Addis Ababa, Ethiopia: Oromia Agriculture and Rural Development Bureau (OARDB).

Parrish, J.D., Braun, D.P. and Unnasch, R.S. (2003). Are we conserving what we say we are? Measuring ecological integrity within protected areas. BioScience, 53, 851-860.

Quinn, G. and Keough, M. (2002). Experimental design and data analysis for biologists. Cambridge, United Kingdom: Cambridge University Press.

Stephens, P.A., D'sa, C.A., Sillero-Zubri, C. and Williams, N.L. (2001). Impact of livestock and settlement on the large mammalian wildlife of Bale
Mountains National Park, Southern Ethiopia. Biological Conservation, 100: 307-322.

Struhsaker, T.T., Struhsaker, P.J. and Siex, K.S. (2005). Conserving Africa's rain forests: problems in protected areas and possible solutions. Biological Conservation, 123: 45-54.

Teshome, E. Kinahan, A.A. and Randall, D. (2011). The Changing Face of the Bale Mountains National Park over 32 years: A Study of Land Cover Change. Walia-Special Edition on the Bale Mountains, 118-130.

van Schaik, C.P., Terborgh, J. and Dugelby, D. (1997). The silent crisis: the state of the rainforest nature reserves. In R. Kramer, C.P. van Schaik and J. Johnson (eds.), The last stand: protected areas and the defence of tropical biodiversity (pp. 64-89). Oxford, United Kingdom: University Press.

Williams, S., Vivero Pol, J.L., Spawls, S., Shimelis, A. and Kelbessa, E. (2004). Ethiopian Highlands. In R.A. Mittermeier, P.R. Gill, M. Hoffmann, J. Pilgrim, T. Brooks, C.G. Mittermeier, J. Lamoreux and G.A.B. Da Fonseca (eds.), Hotspots revisited (pp. 262-273). Mexico City, USA: CEMEX Publisher. 